\title{
COMPARISON BETWEEN CYTOLOGY AND HISTOPATHOLOGY TO EVALUATE ENDOMETRITIS IN DAIRY COWS
}

\author{
Derrar Sofiane $^{1}$, Mohamed Amine Ayad ${ }^{1}$, Meliani Samia ${ }^{2}$, Hemida Houari ${ }^{1}$, \\ Saim Mohamed Said ${ }^{1}$, Imen Safer1 \\ ${ }^{I}$ The veterinary sciences institute, Ibn Khaldoun University of Tiaret, Algeria; \\ ${ }^{2 *}$ Nature and life sciences faculty of Ibn Khaldoun University of Tiaret, Algeria; \\ "Corresponding Author Meliani Samia, email: meianisamia@hotmail.com;
}

Received January 2020; Accepted February 2020; Published March 2020;

DOI: https://doi.org/10.31407/ijees10.204

\begin{abstract}
This study aims first at evaluating the concordance between both cytological and histological results, and at assessing the homogeneity of inflammation in the cytological and histological samples within the genital tract. Cytology is currently the standard technique for the diagnosis of the endometritis in postpartum cow based on a sample that is taken by a sterile cytobrush or a swab in the uterine body. However, cytology evaluates only the condition of the mucosa, for more, at a single site of the genital tract. An ex vivo study was implemented on 30 uteri collected from a slaughterhouse in Tiaret center. The researcher took two samples from 4 different sites of the uterus - cervix, uterine body, right horn and left horn- one for cytological examination and one for the histological. It has been identified that there is a poor match between cytology and histology $(\mathrm{P}=0.02)$ noting that the epitheliumoften absent in the blades- was not taken into consideration. Besides, according to of the research findings, the intersite homogeneity of cytological and histological specimens was not present, which can distort or underestimate the inflammatory state of the uterus. Also, the cervix can show inflammation without being an inflammation of other sites and vice versa. In addition, the Neutrophil levels of both horns and uterine body were in good concordance for cytology test. In conclusion, cytological examination is still the easiest to achieve, but it may underestimate the degree of uterine inflammation; whereas, uterine biopsy provides more results, but its practice is very difficult to perform.
\end{abstract}

Keywords: Cytology, Histology, Neutrophil, Diagnosis, Endometritis, Cow. 